\title{
Global expansion of efforts to control peritoneal metastases
}

\section{Expansión global de los esfuerzos para el control de las metástasis peritoneales}

\author{
- Paul H. Sugarbaker, MD, FACS, FRCS1
}

'Washington Cancer Institute (Washington, D.C., USA).

It is my great pleasure to comment on the manuscripts that report the Colombian experience in the management of peritoneal metastases. These data establish the Fundación Santa Fe de Bogotá as the referral center for peritoneal metastases in Colombia'. The emergence of national centers of excellence, such as this one in Bogota, has been extremely productive for the successful development of these management strategies around the globe. The centralization of patients within a single institution accelerates the cognitive and technical skills necessary to rapidly ascend the steep learning curve ${ }^{2,3}$. My congratulations to these authors for their success demonstrated in the Colombian Journal of Hematology and Oncology'.

The centralization process early in the development of cytoreductive surgery (CRS) and hyperthermic intraperitoneal chemotherapy (HIPEC) has consistently shown itself to be a successful strategy. In the United States, centers in Washington, DC ${ }^{4}$, Winston-Salem, NC ${ }^{5}$ and Pittsburgh, $\mathrm{PA}^{6}$ created a platform for further development. Currently, approximately 120 institutions in the United States are accepting patients with peritoneal metastases for definitive treatment.

In 1994, Basingstoke consolidated for the United Kingdom treatments for pseudomyxoma peritonei adding an essential management capability to the treatment of appendiceal mucinous neoplasms. This has now been extended to treatment of selected patients with peritoneal metastases from colorectal cancer. Also, two new treatment centers for CRS and HIPEC in Manchester and Brisbain are currently accepting patients ${ }^{7}$. In France, the centers in Lyon and Villejuif persisted in their own institutional efforts so successfully that currently approximately 26 peritoneal metastases treatment centers offer therapies for peritoneal metastases from ovarian, appendiceal, colorectal, and gastric cancer-10. Also, the early and dedicated laboratory and clinical research at Instituto Tumori in Milan must be mentioned"1 .
The leadership demonstrated in Regensburg for Germany has facilitated an active German program in peritoneal surface oncology ${ }^{12}$. In Spain, eight centers are active and the Spanish Group of Peritoneal Surface Malignancy (GECOP) meets annually. The international efforts are reexamined biannually at the International Congress of the Peritoneal Surface Oncology Group (PSOGI). The next meeting is in Amsterdam on October 8-11, 2014.

However, successful the efforts in USA and Europe, the efforts in Central and South America are definitely worthy of our applause. Perhaps the original success story was in Buenos Aires, Argentina and the focus was ovarian cancer. Huerta and coworkers reported on 89 patients with ovarian cancer treated by cytoreductive surgery and perioperative chemotherapy with promising results ${ }^{14}$. In Sao Paolo, Brazil, Akaishi and colleagues published their success with CRS and HIPEC in 46 patients $^{15}$. Other centers in Rio de Janeiro and Sao Paolo are active and we await publication to document their efforts.

In Mexico, the CRS and HIPEC centers have been regionally distributed as part of the Regional Hospitals of High Specialties (HRAE) system. Under the leadership of Jesús Esquivel, high quality work is being performed in Oaxaca, Guadalajara, Mérida, México City and Toluca. Jesús Esquivel has made a determined effort to facilitate continued progress and a continued high level of expertise within México ${ }^{16}$.

Although the publication by Otero and colleagues document success in the past, the future requires our continued collaborative efforts. Yes, the Fundación Santa Fe de Bogotá deserves congratulations for its efforts. However, we now expect from them an educational effort that will permeate throughout Colombia. This effort must educate general surgeons and oncologists regarding the proper patients to be referred in a timely manner to the treatment center in Bogotá. The indications for CRS and HIPEC and the important quantitative 
prognostic indicators must be taught. In addition, the development of new centers is mandatory in order to adequately manage the expanding number of patients that will benefit.

Finally, as CRS reaches its peak in terms of a complete surgical response within the abdomen and pelvis, the inadequacies of perioperative chemotherapy, both HIPEC and EPIC to maintain that local-regional control becomes more and more obvious. Natural drug resistance to chemotherapy agents currently available is a major issue. Also, because a large proportion of patients have neoadjuvant chemotherapy prior to CRS and HIPEC, acquired drug resistance occurs. An expectation that a single 60-90 minute pulse of HIPEC treatment can eradicate the last cancer cell in a majority of patients may be unrealistic. Long-term bidirectional chemotherapy (intravenous and intraperitoneal) using an intraperitoneal port is indicated in many patients ${ }^{17}$. The goal of these efforts of CRS and perioperative chemotherapy is to eliminate peritoneal metastases and local-regional recurrence from the natural history of gastrointestinal and gynecologic malignancy ${ }^{18}$.

\section{References}

1. Otero JM, Arias F, Londoño $E$, Becerra $H$, Mora $M$, Carranza $H$, et al. Peritoneal cytoreductive surgery and intraperitoneal chemotherapy: five years of experience at The Fundación Santa Fe de Bogotá (ONCOLGroup - ATIA study). Revista Colombiana de Hematología y Oncología (en prensa).

2. Smeek RM, Verwaal VJ, Zoetmulder FA. Learning curve of combined modality treatment in peritoneal surface disease. $\mathrm{Br} \mathrm{J}$ Surg. 2007;94(11):1408-14.

3. Mohamed F, Moran BJ. Morbidity and mortality with cytoreductive surgery and intraperitoneal chemotherapy: the importance of a learning curve. Cancer J. 2009;15(3):196-9.

4. Sugarbaker PH, Jablonski KA. Prognostic features of 51 colorectal and 130 appendiceal cancer patients with peritoneal carcinomatosis treated by cytoreductive surgery and intraperitoneal chemotherapy. Ann Surg. 1995;221(2):124-32.

5. Loggie BW, Fleming RA, McQuellon RP, Russell GB, Geisinger $K R$. Cytoreductive surgery with intraperitoneal hyperthermic chemotherapy for disseminated peritoneal cancer of gastrointestinal origin. Am Surg. 2000;66(6):561-8.

6. Austin F, Mavanur A, Sathaiah M, Steel J, Lenzner D, Ramalingam L, et al. Aggressive management of peritoneal carcinomatosis from mucinous appendiceal neoplasms. Ann Surg Oncol. 2012;19(5):1386-93.

7. Youssef H, Newman C, Chandrakumaran K, Mohamed F, Cecil TD, Moran BJ. Operative findings, early complications, and long-term survival in 456 patients with pseudomyxoma peritonei syndrome of appendiceal origin. Dis Colon Rectum. 2011;54(3):293-9.

8. Glehen $O$, Mithieux F, Osinsky D, Beaujard AC, Freyer G, Guertsch $\mathrm{P}$, et al. Surgery combined with peritonectomy procedures and intraperitoneal chemohyperthermia in abdominal cancers with peritoneal carcinomatosis: a phase II study. J Clin Oncol. 2003;21(5):799-806.

9. Elias D, Antoun S, Goharin A, Otmany AE, Puizillout JM, Lasser P. Research on the best chemohyperthermia technique for treatment of peritoneal carcinomatosis after complete resection. Int J Surg Investig. 2000;1(5):431-9.
10. Glehen O, Gilly FN, Boutitie F, Bereder JM, Quenet F, et al.; French Surgical Association. Toward curative treatment of peritoneal carcinomatosis from nonovarian origin by cytoreductive surgery combined with perioperative intraperitoneal chemotherapy: a multi-institutional study of 1,290 patients. Cancer. 2010;116(24):5608-18.

11. Baratti D, Kusamura S, Nonaka D, Langer M, Andreola S, Favaro $\mathrm{M}$, et al. Pseudomyxoma peritonei: clinical pathological and biological prognostic factors in patients treated with cytoreductive surgery and hyperthermic intraperitoneal chemotherapy (HIPEC). Ann Surg Oncol. 2008;15(2):526-34.

12. Güner $Z$, Schmidt $U$, Dahlke $M H$, Schlitt HJ, Klempnauer J, Piso P. Cytoreductive surgery and intraperitoneal chemotherapy for pseudomyxoma peritonei. Int J Colorectal Dis. 2005;20(2):155-60.

13. Verwaal VJ, van Ruth $S$, de Bree $E$, van Sloothen GW, van Tinteren $\mathrm{H}$, Boot $\mathrm{H}$, et al. Randomized trial of cytoreduction and hyperthermic intraperitoneal chemotherapy versus systemic chemotherapy and palliative surgery in patients with peritoneal carcinomatosis of colorectal cancer. J Clin Oncol. 2003;21(20):3737-43.

14. Huerta E. ASCO Abstract 1432, 1998.

15. Akaishi E, Teixeira F, Katayama M, Mizumoto N, Costa FP, Buzaid $A C$, et al. Peritonectomy for peritoneal carcinomatosis: long-term outcomes from a single Brazilian institution. World J Surg. 2009;33(4):835-9.

16. García-Matus R, Hernández-Hernández CA, Leyva-García O, Vásquez-Ciriaco S, Flores-Ayala G, Navarro-Hernández Q, et al. Cytoreductive surgery and hyperthermic intraperitoneal chemotherapy in the treatment of peritoneal carcinomatosis: initial experience in Oaxaca, México. Am Surg. 2012;78(9):942-6.

17. Sugarbaker PH, Bijelic L. Adjuvant bidirectional chemotherapy using an intraperitoneal port. Gastroenterol Res Pract. 2012;2012:752643.

18. Sugarbaker $\mathrm{PH}$, editor. Cytoreductive surgery \& perioperative chemotherapy for peritoneal surface malignancy. Textbook and video atlas. Woodbury, CT: Cine-Med Publishers; 2012. 